Tropical Journal of Pharmaceutical Research September 2020; 19 (9): 1807-1813

ISSN: $1596-5996$ (print); 1596-9827 (electronic)

(C) Pharmacotherapy Group, Faculty of Pharmacy, University of Benin, Benin City, 300001 Nigeria.

Original Research Article

http://dx.doi.org/10.4314/tjpr.v19i9.2

\title{
Glycyrrhizin inhibits the invasion and metastasis of breast cancer cells via upregulation of expressions of miR-200c and e-cadherin
}

\author{
Lihong $\mathrm{He}^{1}$, Xiaorui Wang ${ }^{1}$, Qing $\mathrm{Ma}^{2}$, Weipeng Zhao ${ }^{1}$, Yongsheng Jia ${ }^{1}$, Guolei \\ Dong $^{1}$, Yuehong Zhu ${ }^{1}$, Xiaochen Jia ${ }^{1}$, Zhongsheng Tong ${ }^{1 *}$ \\ ${ }^{1}$ Department of Breast Cancer, Tianjin Medical University Cancer Institute and Hospital, ${ }^{2}$ Department of Oncology, General \\ Hospital of Tianjin Medical University, Tianjin, PR China \\ *For correspondence: Email: ajng9u@163.com
}

Sent for review: 5 June 2020

Revised accepted: 27 August 2020

\begin{abstract}
Purpose: To determine the inhibitory effect of glycyrrhizin (GLA) on cell invasion and metastasis in mammary carcinoma cells, and the mechanisms of actions involved.

Methods: The effect of GLA at different concentrations on proliferation of breast cancer MDA-MB-231 and BT549 cells was assayed by MTT method. Transwell assay was used to determine the effect of GLA at different concentrations on invasiveness and metastasis of breast cancer MDA-MB-231 and BT549 cells. The influence of LGA on expressions of microRNA-200c and miR-200c was assayed by reverse transcriptase-polymerase chain reaction (RT-PCR).

Results: There was no statistically significant difference in cell proliferation amongst cells treated with 5 and $20 \mu M$ GLA and untreated breast cancer cells. However, the proliferation of cells treated with $40 \mu \mathrm{M}$ GLA was significantly reduced $(p<0.05)$. In the cell invasion and migration experiments, cell population transferred to the base of Transwell chamber in the two cell lines treated with GLA was markedly decreased, relative to cells without GLA treatment, while the number of cells decreased with increase in GLA concentration $(p<0.05)$. Results from image-pro-plus analysis revealed that the population of cells quantitatively crossing the Transwell compartment membrane decreased with increase in GLA concentration $(p<0.05)$. The expression of e-cadherin was increased by GLA treatment in a concentration-dependent manner. Moreover, GLA treatment led to significant changes in amounts of miR-200s $a, b$ and $c$, with changes in miR-200c being the most significant $(p<0.05)$.

Conclusion: GLA suppresses the invasiveness and metastasis of breast cancer MDA-MB-231 and BT549 cells via upregulation of the expressions of miR-200c and e-cadherin. These findings provide a theoretical basis for the development of new breast cancer drugs.
\end{abstract}

Keywords: Glycyrrhiza, GLA, miR-200c, E-cadherin, Inhibition, Breast cancer cells, Invasion, Metastasis

This is an Open Access article that uses a fund-ing model which does not charge readers or their institutions for access and distributed under the terms of the Creative Commons Attribution License (http://creativecommons.org/licenses/by/4.0) and the Budapest Open Access Initiative (http://www.budapestopenaccessinitiative.org/read), which permit unrestricted use, distribution, and reproduction in any medium, provided the original work is properly credited.

Tropical Journal of Pharmaceutical Research is indexed by Science Citation Index (SciSearch), Scopus, International Pharmaceutical Abstract, Chemical Abstracts, Embase, Index Copernicus, EBSCO, African Index Medicus, JournalSeek, Journal Citation Reports/Science Edition, Directory of Open Access Journals (DOAJ), African Journal Online, Bioline International, Open-J-Gate and Pharmacy Abstracts

\section{INTRODUCTION}

Mammary frequently carcinoma is among the most diagnosed malignancies among women, and a major reason for female mortality in the world. In recent years, the incidence of breast cancer which seriously threatens women's health, has been rising year by year [1]. 
Malignant tumors are the major factors responsible for death of Chinese people, due to metastasis and invasiveness of cancer cells [2]. E-cadherin is a class of calcium-dependent transmembrane glycoproteins that adhere to each other among the same epithelial cells, and participate in the formation and maintenance of intercellular connections [3]. Studies have found that partial and complete deletion of e-cadherin lead to low differentiation, high aggressiveness and poor clinical prognosis of tumors [4]. Glycyrrhizin (GLA) is a polyphenolic flavonoid compound and a major bioactive component of glycyrrhizin. It exerts strong anti-free radical and anti-oxidation effects, and prevents atherosclerosis and cell aging [5]. Recent studies have shown that GLA has some anti-tumor effects, but no specific mechanism has been reported [6]. The purpose of this study was to determine the relationship between GLA-induced inhibition of breast cancer cell invasion and metastasis, and up-regulation of e-cadherin expression through miR-200c.

\section{EXPERIMENTAL}

\section{Cell lines, reagents and equipment}

Breast cancer MDA-MB-231 and BT549 cell lines were provided by cell library of the ATCC.

Fibronectin and MEM were products of Sigma, USA. Leibovitz's L.15 medium was purchased from Gibco, USA. Mycoplasma free FBS was obtained from Hangzhou Sijiqing Biological Engineering Co. Ltd, China. Crystal violet staining solution, BSA, Western blot and IP cell lysis solution were products of China Biyun Tian Biological Engineering Co. Ltd. Transwell chamber was obtained from Corning, USA, while RT quantitative PCR reagents for miRNA were purchased from TaKaRa.

The instruments used, and their makers (in parenthesis) were: Cell incubator (Thermo, USA); Ultra-clean worktable (Airtech, USA); CKX41 inverted light microscope (Olympus, Japan); CS-15R bench high speed cryogenic centrifuge (Beckman, USA); small wet electrical transfer tank (Bio-laboratories, USA); Ceres908 automatic enzyme marker (Bio-tek, USA); Model 7300 real-time fluorescent $P C R$ instrument $(A B I$, USA); DYY-6C voltage and steady current meter (Nanjing Honglong Instrument \& Equipment Instruments); and $-80^{\circ} \mathrm{C}$ ultra-low temperature chamber (Revco, USA).

\section{Cell culture}

Breast cancer MDA-MB-231 cell lines were cultured in L-15 medium containing penicillin and streptomycin (100U/mL each), and $10 \% \mathrm{FBS}$, in a $\mathrm{CO}_{2}$-free incubator at $37^{\circ} \mathrm{C}$. The breast cancer BT549 cell line was cultured in 1640 medium under similar conditions. When the adherent cells reached more than $80 \%$ confluence, the cells were digested with trypsin for $1 \mathrm{~min}$. Thereafter, the adherent cells were made into a single cell suspension by blowing with an elbow straw, and kept for use in subsequent experiments.

\section{Drug treatment}

The medium was replaced with fresh one when the cells became adherent to the wall for $24 \mathrm{~h}$. Then, GLA was added at doses of 5, 10, and 40 $\mu \mathrm{M}$. Untreated cells served as control. The culture medium was shaken horizontally, and the treatment was carried out for 2 days. The culture medium was changed once every 2 days, and marked according to the added concentration.

\section{Lymphocyte proliferation assay}

Breast cancer MDA-MB-231 and BT549 cell lines were maintained in $\mathrm{L}-15$ medium and 1640 medium, respectively, for 4 days. The two cell lines were inoculated into 96-well plates and cultured at $37{ }^{\circ} \mathrm{C}$ in a $\mathrm{CO}_{2}$-free incubator. Two days after inoculation and culture in a 96-well plate, $1 \mathrm{ml}$ MEM medium was transferred to a 1.5 $\mathrm{mL}$ centrifuge tube, and the required treatment drugs and transfection reagent were added. After the old medium was sucked out, medium containing drugs was added, and incubation was carried out at $37^{\circ} \mathrm{C}$ in a $\mathrm{CO}_{2}$-free incubator. After treatment for 24 and 48h, diluted MTS fresh MEM medium was added to the 96-well plate (200 $\mu \mathrm{L} /$ well), followed by addition of MTS (10 $\mu \mathrm{L} /$ well) and incubation at $37^{\circ} \mathrm{C}$ for $4 \mathrm{~h}$. Finally, the absorbance of each well was read at $490 \mathrm{~nm}$ in an automatic enzyme label analyzer, and the corresponding cell number was calculated from a standard curve for each cell line. Six parallel cells were set for each treatment group.

\section{Cell migration assay}

A 24-well plate and Matrigel invasion chamber were prepared. The cell lines were digested with trypsin and centrifuged. Then, the cells were taken up in serum-free and double-antibody medium, at a cell density of $1 \times 10^{5}$ cells $/ \mathrm{ml}$. Matrigel was put in a 24-well plate, with $1 \times$ $10^{5} / \mathrm{ml}$ cell suspension in each well. The lower chamber contained $600 \mu \mathrm{L} 10 \%$ FBS as culture medium. After incubation for $12 \mathrm{~h}$, the chamber was removed and placed in a new 24-well plate in a super-clean table.

Trop J Pharm Res, September 2020; 19(9): 1808 
Then, the medium was drained slowly, and cells were PBS-rinsed, drained as much as possible, and air-dried. In the transfer chamber, $500 \mu \mathrm{L}$ of methanol was added to 24-well plate. This was followed with washing twice with PBS. Cells that did not pass through the chamber were wiped with a cotton swab, washed with PBS, and airdried. Then, $500 \mu \mathrm{L}$ of crystal violet was put into the well plate, after which it was PBS-rinsed two times. Then, the chamber was placed in a slide and photographed with a microscope.

\section{Determination of cell invasion}

A 24-well plate and Matrigel invasion chamber was prepared. The chamber was placed on super clean table. The original solution of Matrigel was diluted with serum-free and double antibody-free medium in a volume ratio of $1: 8$, and $100 \mu \mathrm{L}$ was added to the chamber, which was dried in a cell incubator for $2 \mathrm{~h}$. After digesting the cells with trypsin, the digest was centrifuged, and the cells $\left(1 \times 10^{5}\right.$ cells $\left./ \mathrm{mL}\right)$ were put in serum-free and double antibody-free medium.

Matrigel were placed in a 24-well plate, with cell suspension $\left(1 \times 10^{5} / \mathrm{mL}\right)$ in each chamber. The lower chamber culture medium was $600 \mu \mathrm{L}$ of 10 $\%$ FBS. Then, the cells were incubated for $12 \mathrm{~h}$. Thereafter, the chamber was placed in a new 24well plate on a super-clean table, and the medium was drained slowly. The cells were PBSrinsed two times, drained as much as possible, and air-dried. In the transfer chamber, the cells were fixed with methanol $(500 \mu \mathrm{L})$ for $25 \mathrm{~min}$. This was followed with washing twice with PBS. Cells that did not pass through the chamber were wiped off with a cotton swab, washed with PBS, and air-dried. Then, $500 \mu \mathrm{L}$ of crystal violet was put in the well plate in the invasion chamber for 25 min, after which it was PBS-rinsed two times. Then, the chamber was placed in a slide and photographed with a microscope.

\section{Real time Polymerase Chain Reaction (PCR)}

Trizol (1 $\mathrm{mL})$ was added to each petri dish, and the mixture was repeatedly pumped, blown and mixed until the cells were fully lysed. The lysate was taken up in a 1.5-mL tube with $200 \mu \mathrm{L}$ of chloroform. The mixture was shaken vigorously for $30 \mathrm{sec}$ to mix well. Then, it was centrifuged in a desktop centrifuge for $20 \mathrm{~min}$. Then, $500 \mu \mathrm{L}$ of the supernatant was mixed with an equivalent volume of isopropanol, and the mixture was centrifuged using the desktop centrifuge for 15 min. The supernatant was rinsed twice with $75 \%$ alcohol, and centrifuged again for $2 \mathrm{~min}$. The alcohol was evaporated off, followed by addition of $50 \mu \mathrm{L}$ of DEPC- $\mathrm{H}_{2} \mathrm{O}$ freezing at $-20^{\circ} \mathrm{C}$ prior to use. Subsequently, Real Time PCR reaction was carried out. After the reaction, the amplification curve and fusion curve of Real Time PCR reaction were confirmed, and the standard curve was prepared for PCR quantification.

\section{Western blotting analysis}

The cell culture medium was discarded, washed twice with $5 \mathrm{~mL}$ normal saline, and the petri dish was placed on ice. The lysis buffer was prepared, and different volumes of lysis buffer were added according to the cell density in each culture dish. Cells were directly scraped with a cell scraper and transferred into a $1.5 \mathrm{~mL}$ centrifuge tube for $30 \mathrm{~min}$ in an ice bath. The cells were centrifuged for $30 \mathrm{~min}$, and the supernatant was stored at $-20^{\circ} \mathrm{C}$ after packing. The BCA method was used to determine the protein concentration. Then, the proteins were subjected to SDS-PAGE, followed by transfer to polyvinylidene membrane transfer, blocking, and incubation with primary and secondary antibodies. The relative protein expressions were determined using enhanced chemiluminescence kit.

\section{Statistical analysis}

The SPSS 20.0 software was used for statistical analysis of data. Measurement data are presented as mean \pm SD. Comparison between two groups was done with $t$-test. Count data were expressed in \%), and were statistically analyzed using $X^{2}$ test. Statistical significance was assumed at $p<0.05$.

\section{RESULTS}

\section{Impact of different GLA treatments on cell proliferative capacity}

As shown in Table 1, there were no statistically significant differences in proliferation amongst cells exposed to $5 \mu \mathrm{M}$ and $20 \mu \mathrm{M}$ GLA, and untreated control $(p>0.05)$. However, GLA at a dose of $40 \mu \mathrm{M}$ significantly decreased proliferation of breast cancer cells.

\section{Effect of different GLA treatments on breast cancer cell invasion and metastasis}

In the cell invasion and migration experiments, the population of cells transferred to the base of the Transwell chamber in the two cell lines treated with GLA was markedly decreased, relative to cells without GLA treatment, and the number of cells decreased with increase in GLA concentration.

Trop J Pharm Res, September 2020; 19(9): 1809 
Table 1: Effect of different GLA treatments on proliferative potential of mammary cancer cells

\begin{tabular}{lcccc}
\hline GLA concentration & \multicolumn{2}{c}{ MDA-MB-231 Cell } & \multicolumn{2}{c}{ BT549 Cell } \\
\cline { 2 - 5 }$(\boldsymbol{\mu M})$ & $\mathbf{2 4 h}$ & $\mathbf{4 8 h}$ & $\mathbf{2 4 h}$ & $\mathbf{4 8 h}$ \\
\hline 0 & $108.46 \pm 20.48$ & $108.41 \pm 23.71$ & $111.78 \pm 23.46$ & $112.85 \pm 23.85$ \\
5 & $107.26 \pm 18.23$ & $105.33 \pm 12.46$ & $110.08 \pm 16.49$ & $110.51 \pm 13.20$ \\
10 & $101.56 \pm 9.41$ & $100.26 \pm 9.46$ & $108.51 \pm 10.33$ & $109.79 \pm 10.31$ \\
20 & $98.46 \pm 9.46$ & $98.33 \pm 8.46$ & $106.23 \pm 9.47$ & $105.49 \pm 9.51$ \\
40 & $68.26 \pm 13.85^{\text {abcd }}$ & $60.49 \pm 8.21^{\text {abcd }}$ & $68.12 \pm 5.46^{\text {abcd }}$ & $61.23 \pm 5.49^{\text {abcd }}$ \\
\hline
\end{tabular}

${ }^{a} P<0.05$, vs untreated cells; ${ }^{b} p<0.05$, vs $5 \mu \mathrm{M}$ GLA dose; ${ }^{c} p<0.05$, vs $10 \mu \mathrm{M}$ GLA dose; ${ }^{d} p<0.05$, vs $20 \mu \mathrm{M}$ GLA dose

Results from image-pro-plus analysis showed that the number of cells quantitatively crossing the Transwell compartment membrane decreased with increase in GLA concentration ( $p$ $<0.05$ ). These results are shown in Figure 1, Figure 2, Figure 3 and Figure 4, and in Table 2.

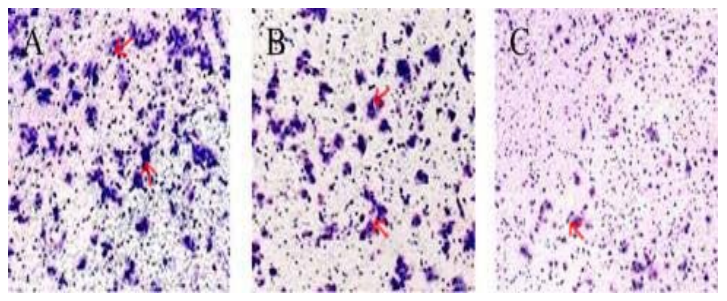

Figure 1: Effect of different GLA treatments on MDAMB-231 cell migration. A: Image of untreated cells; B: cells exposed to $5 \mu \mathrm{M}$ GLA; C: Image of cells exposed to $10 \mu \mathrm{M}$ GLA; D: Image of cells treated with $20 \mu \mathrm{M}$ GLA

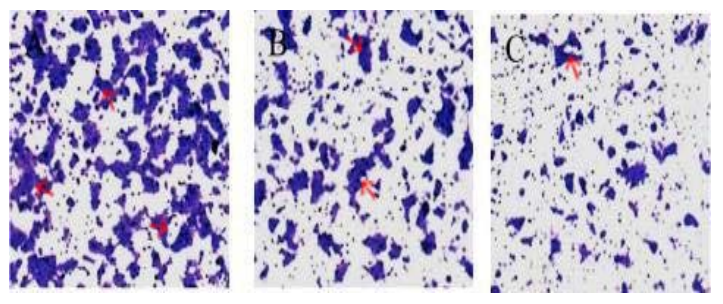

Figure 2: Effect of different GLA treatments on the migration of BT549 cells. A: Image of untreated BT549 cells; B: Image of BT549 cells exposed to $5 \mu \mathrm{M}$ GLA; C: Image of BT549 cells treated with $10 \mu$ M GLA; D: Image of BT549 cells treated with $20 \mu \mathrm{M}$ GLA

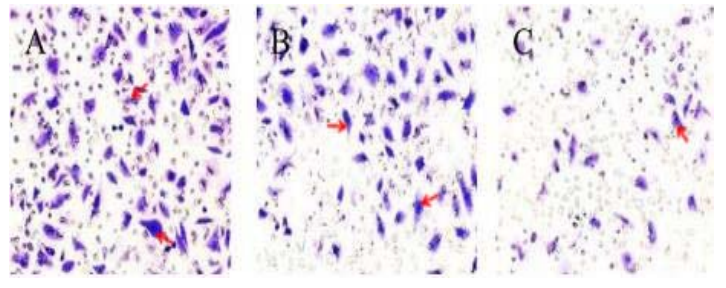

Figure 3: Effect of different GLA treatments on the invasion of MDA-MB-231 cells. A: Image of control cells; B: Image of cells exposed to $5 \mu \mathrm{M}$ GLA; C: Image of cells exposed to $10 \mu \mathrm{M}$ GLA; D: Image of cells exposed to $20 \mu \mathrm{M}$ GLA.
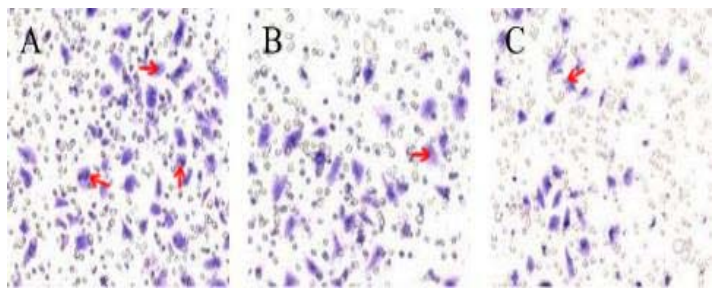

Figure 4: Effect of different GLA treatments on the invasion of BT549 cells. A: Image of untreated BT549 cells; B: Image of BT549 cells exposed to $5 \mu \mathrm{M}$ GLA; C: Image of BT549 cells treated with $10 \mu$ M GLA; D: Image of BT549 cells treated with $20 \mu \mathrm{M}$ GLA

\section{Effect of different GLA treatments on breast cancer cell adhesion proteins}

As shown in Figure 5, treatment with GLA increased e-cadherin expression in a concentration-based fashion.

Table 2: Effect of different GLA treatments on invasiveness and metastasis of mammary carcinoma cells (mean $\pm \mathrm{SD})$

\begin{tabular}{lcccc}
\hline \multirow{2}{*}{ GLA concentration } & \multicolumn{2}{c}{ MDA-MB-231 Cells } & \multicolumn{2}{c}{ BT549 Cells } \\
\cline { 2 - 5 } & \multicolumn{1}{c}{ Migration } & Invasion & Migration & Invasion \\
\hline 0 & $132.16 \pm 30.46$ & $75.16 \pm 26.13$ & $152.41 \pm 35.21$ & $119.84 \pm 16.52$ \\
$5 \mu \mathrm{M}$ & $70.16 \pm 15.40^{\mathrm{a}}$ & $62.38 \pm 12.24^{\mathrm{a}}$ & $84.26 \pm 20.38^{\mathrm{a}}$ & $68.25 \pm 19.74^{\mathrm{a}}$ \\
$10 \mu \mathrm{M}$ & $42.13 \pm 8.23^{\mathrm{ab}}$ & $38.47 \pm 6.42^{\mathrm{ab}}$ & $35.16 \pm 10.02^{\mathrm{ab}}$ & $30.16 \pm 5.16^{\mathrm{ab}}$ \\
$20 \mu \mathrm{M}$ & $35.16 \pm 6.12^{\mathrm{abc}}$ & $30.26 \pm 6.75^{\mathrm{abc}}$ & $21.33 \pm 8.16^{\mathrm{abc}}$ & $16.43 \pm 5.18^{\mathrm{abc}}$ \\
\hline
\end{tabular}

${ }^{\mathrm{a}} P<0.05$, vs untreated cells; ${ }^{\mathrm{b}} p<0.05$, vs $5 \mu \mathrm{M}$ GLA; ${ }^{\mathrm{c}} p<0.05$, vs $10 \mu \mathrm{M}$ GLA 


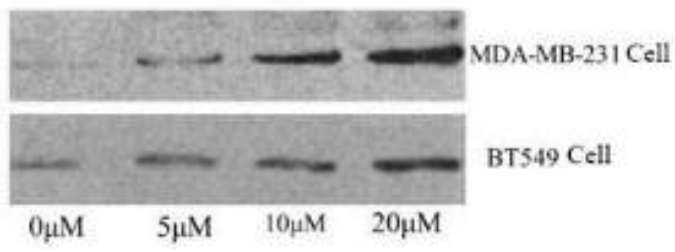

Figure 5: Effect of different GLA treatments on ecadherin expression in MDA-MB-231 cells and BT549 cells

\section{Effect of different GLA treatments on} expression of $\mathrm{miR}-200 \mathrm{c}$

Treatment with GLA caused significant alterations in expressions of miR-200a, miR$200 \mathrm{~b}$ and miR-200c, with miR-200c showing the most significant change $(p<0.05$; Table 3$)$.

Table 3: Effect of different GLA treatments on the expression of miR-200c in breast cancer cells (mean \pm $\mathrm{SD})$

\begin{tabular}{lcccc}
\hline \multirow{2}{*}{ Index } & \multicolumn{2}{c}{ MDA-MB-231 Cell } & \multicolumn{2}{c}{ BT549 Cell } \\
\cline { 2 - 5 } & Control & GLA & Control & GLA \\
\hline miR- & $1.00 \pm$ & $1.56 \pm$ & $1.00 \pm$ & $1.86 \pm$ \\
200a & 0.00 & $0.26^{\mathrm{a}}$ & 0.00 & $0.12^{\mathrm{a}}$ \\
miR- & $1.00 \pm$ & $1.03 \pm$ & $1.00 \pm$ & $2.09 \pm$ \\
200b & 0.00 & $0.13^{\mathrm{a}}$ & 0.00 & $0.16^{\mathrm{a}}$ \\
miR- & $1.00 \pm$ & $2.16 \pm$ & $1.00 \pm$ & $3.28 \pm$ \\
$200 \mathrm{c}$ & 0.00 & $0.31^{\mathrm{a}}$ & 0.00 & $0.41^{\mathrm{a}}$ \\
\hline${ }^{\mathrm{a} P<0.05, \text { vs control }}$ & & &
\end{tabular}

\section{DISCUSSION}

Mammary carcinoma is among the most frequently diagnosed malignancies in women, and it has attracted extensive attention from medical scholars due to its increasing incidence. It has been found that in situ breast cancer is not fatal: it can be cured through surgical resection in combination with chemotherapy and radiotherapy [7]. However, $30-40 \%$ of patients still have tumor metastasis and invasion, especially in lung, liver and bone. Metastasis is the main reason behind failure in breast cancer therapy. Metastasis increases the resistance of tumors to treatment measures, thereby affecting prognosis of patients, and constituting serious threat to life [8].

Glycyrrhizin (GLA) is one of the main flavonoids in glycyrrhiza. It has antioxidant and antiinflammatory properties, as well as lipidregulatory and blood glucose control effects [9]. Recent studies have found that high concentrations of licorice inhibited the proliferation of breast cancer cells. It has been reported that licorice root extract inhibited invasion, metastasis and angiogenesis in MDA-
MB-23I human breast cancer cells and in A549 human non-small cell lung cancer cells by blocking the FAK/Rho signaling pathway [10]. Glycyrrhizin (GLA) has a wide range of biological effects, including significant mitigation of free radical-induced damage to $\mathrm{LDL}, \mathrm{DNA}$ and cell membranes [11]. In addition, GLA inhibits osteoclast production, exerts antifungal and antiinflammatory effects, reverses fatigue, reduces blood sugar, and decreases obesity and hyperlipidemia [12].

In this study, there were no statistically significant differences in proliferation amongst cancer cells treated with $5 \mu \mathrm{M}$ and $20 \mu \mathrm{M}$ GLA, and untreated cells. However, GLA at a dose of $40 \mu \mathrm{M}$ markedly reduced proliferation of breast cancer cells. In the cell invasion and migration experiments, the population of cells transferred to the Transwell chamber base in the two cell lines treated with GLA was markedly reduced, relative to cells without GLA treatment, and the number of cells decreased with increase in GLA concentration. Results from image-pro-plus analysis revealed that the number of cells quantitatively crossing the Transwell compartment membrane decreased with increase in GLA concentration. These results suggest that GLA inhibited the migratory and invasive potential of the two cell lines.

Epithelial-mesenchymal transformation is the process involved in the transformation of epithelial cells into cells with mesenchymal phenotypes via specific procedures. These procedures cause the epithelial cells to lose epithelial phenotypic characteristics such as cell polarity and connection with the basement membrane, resulting in mesenchymal phenotypic attributes like high migratory, invasive, antiapoptotic, and extracellular matrix-degradative capacities [13]. The adhesion amongst epithelial cells is due to e-cadherin which is needed for epithelial-mesenchymal transformation [14]. The expression level of e-cadherin mRNA is influenced by miRNA. In particular, the bmiR-200 family members are crucial for regulation of ecadherin expression $[15,16]$.

In this study, GLA increased e-cadherin expression in a concentration-based fashion. Moreover, GLA treatment led to significant changes in the expressions of miR-200-a, miR200-b and miR-200-c, with changes in miR-200c being the most significant. This indicates that the inhibitory effect of GLA on the migration and invasion of the cells might be related to the increase in e-cadherin expression through upregulation of the expression of miR-200c. 


\section{CONCLUSION}

This study demonstrates that exposure of breast cancer MDA-MB-231 and BT549 cells to GLA upregulates the expressions of miR-200c and ecadherin, thereby suppressing the invasive and metastatic potentials of breast cancer cells. Thus, the findings provide a theoretical basis for the development of new breast cancer drugs.

\section{DECLARATIONS}

\section{Acknowledgement}

This study was supported by Science and Technology Fundation of Tianjin Municipal Health and Health Committee (no. 2015KZ089); Anticancer Key Technologies R\&D Program of Tianjin (no. 12ZCDZSY16200), and Natural Science Foundation of Tianjin (no. 18JCYBJC91600).

\section{Conflict of interest}

No conflict of interest is associated with this work.

\section{Contribution of authors}

We declare that this work was done by the author(s) named in this article and all liabilities pertaining to claims relating to the content of this article will be borne by the authors. All authors read and approved the manuscript for publication. Zhongsheng Tong conceived and designed the study. Lihong $\mathrm{He}$, Xiaorui Wang, Qing Ma, Weipeng Zhao, Yongsheng Jia, Guolei Dong, Yuehong Zhu, Xiaochen Jia and Zhongsheng Tong collected and analyzed the data, while Lihong He wrote the manuscript.

\section{Open Access}

This is an Open Access article that uses a funding model which does not charge readers or their institutions for access and distributed under the terms of the Creative Commons Attribution License (http://creativecommons.org/licenses/by/ 4.0) and the Budapest Open Access Initiative (http://www.budapestopenaccessinitiative.org/rea d), which permit unrestricted use, distribution, and reproduction in any medium, provided the original work is properly credited.

\section{REFERENCES}

1. Rybicka A, Eyileten C, Taciak B, Mucha J, Majchrzak K, Hellmen E, Krol M. Tumour-associated macrophages influence canine mammary cancer stem-like cells enhancing their pro-angiogenic properties. I Physiol Pharmacol 2016; 67(4): 491-500.

2. Msaki A, Pastò A, Curtarello M, Arigoni M, Barutello G, Calogero RA, Macagno M, Cavallo $F$, Amadori $A$, Indraccolo $S$. A hypoxic signature marks tumors formed by disseminated tumor cells in the BALB-neuT mammary cancer model. Oncotarget 2016; 7(22): 33081-33095.

3. Liu JQ, Feng YH, Zeng S, Zhong MZ. linc01088 promotes cell proliferation by scaffolding EZH2 and repressing p21 in human non-small cell lung cancer. Life Sci 2020; 241: 117134.

4. Zang $C$, Nie $F Q$, Wang $Q$, Sun $M$, Li W, He J, Zhang $M$, Lu KH. Long non-coding RNA LINC01133 represses $K L F 2, P 21$ and E-cadherin transcription through binding with EZH2, LSD1 in non-small cell lung cancer. Oncotarget 2016; 7(10): 11696-11707.

5. Yang $D$, Fang $Y$, Xia $P$, Zhang $X$, Liang $Z$. Diverse responses of tanshinone biosynthesis to biotic and abiotic elicitors in hairy root cultures of Salvia miltiorrhiza and Salvia castanea Diels f. tomentosa. Gene 2018; 643: 61-67.

6. Cai X, Wang $X, \mathrm{Li} \mathrm{J}$, Chen S. Protective effect of glycyrrhizin on myocardial ischemia/reperfusion injuryinduced oxidative stress, inducible nitric oxide synthase and inflammatory reactions through high-mobility group box 1 and mitogen-activated protein kinase expression. Exp Ther Med 2017; 14(2): 1219-1226.

7. Telo S, Halifeoglu I, Ozercan IH. Effects of Stinging Nettle (Urtica Dioica L.) on Antioxidant Enzyme Activities in Rat Model of Mammary Gland Cancer. Iran J Pharm Res 2017; 16(1): 164-170.

8. Gillette $R$, Son MJ, Ton L, Gore AC, Crews D. Passing experiences on to future generations: endocrine disruptors and transgenerational inheritance of epimutations in brain and sperm. Epigenetics 2018; 13(10-11): 1106-1126.

9. leong CC, Sun HG, Wang QP, Ma J. Glycyrrhizin suppresses the expressions of HMGB1 and ameliorates inflammative effect after acute subarachnoid hemorrhage in rat model. J Clin Neurosci 2018; 47: 278284.

10. Li YW, Hu YH, Zhu TT, Chu AZ, Zhu CL. Clinical efficacy of compound glycyrrhizin tablets in the treatment of children with nonalcoholic fatty liver disease. Zhongguo Dang Dai Er Ke Za Zhi 2017; 19(5): 505-509.

11. Yu W, Jin H, Shen A, Deng L, Shi J, Xue X, Guo Y, Liu Y, Liang $X$. Purification of high-purity glycyrrhizin from licorice using hydrophilic interaction solid phase extraction coupled with preparative reversed-phase liquid chromatography. J Chromatogr B Analyt Technol Biomed Life Sci 2017; 1040: 47-52.

12. Wang YY, Chai JX, Sun MQ, He W, Hu X, Zou W, Li H, $L u Y$, Xie C. Glycyrrhizinic acid modulates the immunity of MRL/Ipr mice and related mechanism. Xi Bao Yu Fen Zi Mian Yi Xue Za Zhi 2017; 33(3): 305-309.

Trop J Pharm Res, September 2020; 19(9): 1812 
13. Qi Z, Yuan L, Sun N. Propofol exhibits a tumorsuppressive effect and regulates cell viability, migration and invasion in bladder carcinoma by targeting the microRNA-10b/HOXD10 signaling pathway. Oncol Lett 2019; 18(6): 6228-6236.

14. Neff R, Rush CM, Smith B, Backes FJ, Cohn DE, Goodfellow PJ. Functional characterization of recurrent FOXA2 mutations seen in endometrial cancers. Int $J$ Cancer 2018; 143(11): 2955-2961.
15. Zhang XJ, Wan L, Liu J. Xinfeng Capsule Regulates Platelet Activation by Regulating Lncrna Malat1/Mir155/B-Catenin to Improve Lung Function in Rheumatoid Arthritis. Acta Medica Mediterranea 2019; 35(6): 2921 2926.

16. Huang XG, Yu YP, Jiang XJ. Jzl184 Regulates Related Molecules Through the Akt-Mtor Pathway to Affect the Apoptosis and Metastasis of Colorectal Cancer Tumor Cells. Acta Medica Mediterranea 2019; 35(6): 29392943. 